\title{
UNDERSTANDING THE INTERPRETATON, IMPLEMENTATION, AND IMPACT OF ENGINEERING ETHICS EDUCATION IN CANADA
}

\author{
Emma Jane Randall and David S. Strong \\ Queen's University \\ 14ejr1@queensu.ca and david.strong@queensu.ca
}

\begin{abstract}
Engineers have direct influence on the evolving planet. With the fundamental goal of continually creating a better world, it is essential for engineers to meaningfully understand ethical responsibility and the impact of engineering on society and the environment $[4,15]$. Although efforts have been made to identify the objectives of engineering ethics education (EEE), little has been done to thoroughly investigate the impact EEE is having on individuals' ethical development $[6,7,13]$. Furthermore, there is a large level of uncertainty as to the amount of exposure students have to EEE between programs, as well as the variability of ethics content students experience as a result of diverse interpretation of EEE objectives. The amount of exposure and type of content students are exposed to will affect the impact EEE has on them and hence, it is important to evaluate these aspects of the current implementation of EEE in Canada.

This paper will review literature regarding the current state of EEE within Canada and the objectives of EEE, as well as propose a study to investigate students' experience with EEE throughout undergrad and the impact that engineering ethics education may have on their ethical behaviours within an engineering context.
\end{abstract}

Keywords: Engineering Ethics, Moral Ethics, Professional Ethics, CEAB Graduate Attribute 10, Ethics Education Impact

\section{INTRODUCTION}

Engineering ethics education (EEE) is a relatively modern addition to engineering programs, having only been implemented formally by the Canadian Engineering Accreditation Board (CEAB) in the past 20 years $[2,3]$. Due to both the youth of this field, as well as the inherent nature of ethics to be subjective, EEE currently lacks standardization resulting in uncertainty as to whether this vital graduate attribute is being taught consistently across Canada $[12,15]$. There are multiple studies that have been done at Canadian universities that suggest that EEE is a major area for improvement for engineering programs, but as there is such immense variation in the interpretation and implementation of EEE, the overall current state of engineering ethics education across Canada is unclear [7, 13]. Although preliminary efforts have been made to understand and develop EEE as an educational field, at this point no research has been done to thoroughly investigate the impact that formal engineering ethics education is having on students' ethical beliefs and behaviours [7, 13].

This paper will provide a literature review of the current state of EEE in Canada, delivery methods of $\mathrm{EEE}, \mathrm{CEAB}$ graduate requirements of $\mathrm{EEE}$, and Canadian EEE curriculum and objectives. A mixed methods research study will then be proposed to provide insight into what degree of exposure students are receiving to EEE in Canadian engineering undergraduate programs and investigate the relationship between exposure to EEE and individual ethical beliefs and behaviours. These insights will help to evaluate whether current EEE practice is meeting the general objectives set by the CEAB and will aid to continue to develop a basis for meaningful engineering ethics education.

\section{DEFINITIONS AND RESEARCH SCOPE}

The scope of this project is currently focussed on engineering undergraduate programs within Canada, but given the similarity of graduate attributes for accreditation between Canada and the United States (US), American research will also be used to help inform this study $[2,8]$. The focus of the research as currently proposed will be Canadian undergraduate engineering programs. If further research or preliminary results indicate that it would be valuable to extend the study to investigate the ethical development of engineers beyond the undergraduate level, the scope may be adjusted.

In general, ethics may be broken down into two primary categories; moral ethics and professional ethics. For the purpose of this study, these terms will be defined as follows:

Moral ethics may be defined as standards of conduct that apply to everyone rather than only to members of a special group. Ideally, these standards are ones that 
every rational person wants every other to follow, even if everyone else's following them would mean that they would have to do the same [6]. Professional ethics may be defined as special morally permissible standards of conduct that, ideally, every member of a profession wants every other member to follow, even if that would mean that they would have to do the same [6].

When using the term 'Engineering Ethics Education (EEE)' throughout this paper, this refers to the conveyance of professional engineering ethics to undergraduate students. This includes both formal EEE as delivered via courses, as well as informal EEE which will be defined as engineering experiences throughout an undergraduate period that students perceive to have impacted their ethical development as engineers, such as internship, design clubs, and other extracurricular activities relating to engineering. When discussing exposure to EEE, the focus will be with respect to the amount of time spent on the delivery of EEE, rather than the instruction method.

\section{LITERATURE REVIEW}

\subsection{The Current State of EEE in Canada}

The overall purpose of teaching engineering ethics in undergraduate programs is to produce ethically aware and responsible engineers, with the greater intention in mind of promoting ethical practice $[4,15]$. To address this objective the Canadian Engineering Accreditation Board $(\mathrm{CEAB})$ requires that graduating engineering students must have an "ability to apply professional ethics, accountability, and equity" [5].

There is debate as to what the engineering ethics curriculum should include, as ethics may be considered an individual domain and there is a fear that in teaching ethics there is potential for indoctrination of students to a specific belief system [20]. However, it is agreed that formal professional ethics education is essential for engineers, just as it is for other professions such as law and medicine, as prescribed by governing bodies such as Engineers Canada and provincial licencing bodies [1, 2, 5, 18].

Engineering licencing is done at a provincial level in Canada via a process where candidates complete a certain amount of industry experience under the supervision of a professional engineer, and then complete a licencing exam [1]. For example, in order to become a licenced engineer in Ontario it is necessary to pass the Professional Practice Examination (PPE) given by the self-regulating body of Professional Engineers Ontario (PEO) [18]. This exam emphasizes relevant ethical codes and professional practice standards [18]. Once a person passes the PPE and obtains the required number of months of experience working under the supervision of a professional engineer, they are eligible to apply to become a licenced engineer. Currently, in Ontario there is no mandatory further professional development needed to renew an engineering licence at any point in a person's career, although $\mathrm{PEO}$ is exploring the possibility of implementing a program called Professional Evaluation and Knowledge (PEAK) which may address this by providing professional development resources and regular professional evaluations for licenced engineers [19]. Not having professional development licence renewal requirements is inconsistent with other professions in Canada such as law and accounting, which both require a minimum of between $12-20$ hours of continuing professional development (CPD) annually to maintain an active licence in Ontario [16, 17]. With no mandatory requirement for further training, the minimum standard for engineers' formal ethics education is that which they receive in their undergraduate program.

\subsection{CEAB Requirements for EEE}

In Canada, accreditation of engineering programs is based upon twelve graduate attributes. Engineering ethics is addressed directly by graduate attribute 10 , which states graduates must have "ability to apply professional ethics, accountability, and equity" [5]. The $\mathrm{CEAB}$ requires accredited programs have set amounts of Academic Units within five major categories as defined in Table 1.

Table 1: Academic unit (AU) breakdown of accredited Canadian engineering programs. $1 \mathrm{AU}=50$ minutes of lecture, $0.5 \mathrm{AU}=1$ hour of lab/tutorial work [2].

\begin{tabular}{|l|l|l|}
\hline $\begin{array}{l}\text { Min \# of } \\
\text { AUs }\end{array}$ & Categories & Additional Requirements \\
\hline 195 AU & $\begin{array}{l}\text { Mathematics } \\
\text { (M) }\end{array}$ & \multirow{2}{*}{ Min: M + NS = 420 AU } \\
\hline 195 AU & $\begin{array}{l}\text { Natural } \\
\text { Science (NS) }\end{array}$ & \\
\hline 225 AU & $\begin{array}{l}\text { Engineering } \\
\text { Science (ES) }\end{array}$ & \multirow{2}{*}{ Min: ES + ED = 900 AU } \\
\hline 225 AU & $\begin{array}{l}\text { Engineering } \\
\text { Design (ED) }\end{array}$ & \\
\hline 225 AU & $\begin{array}{l}\text { Complementary } \\
\text { Studies (CS) }\end{array}$ & $\begin{array}{l}\text { a. Subject matter that deals with } \\
\text { the humanities and social } \\
\text { sciences } \\
\text { b. Oral and written } \\
\text { communications } \\
\text { c. Professionalism, ethics, } \\
\text { equity and law } \\
\text { d. The impact of technology } \\
\text { and/or engineering on society } \\
\text { e. Health and safety } \\
\text { f. Sustainable development and } \\
\text { environmental stewardship } \\
\text { g. Engineering economics and } \\
\text { project management }\end{array}$ \\
\hline
\end{tabular}


The minimum number of Academic Units (AU) in total must be 1950. The additional 405 AUs over and above those outlined above "may be assigned to any learning activity that complements the technical content of the curriculum, is consistent with the program objectives. and is assigned academic credit by the institution" [2]. Engineering ethics falls under the category of Complementary Studies, as do language, humanities, engineering economics, sustainability, and professional skills [2]. The CEAB graduate accreditation system is very similar to that used in the United States by the Engineering Accreditation Commission (ABET) [9].

Within the CEAB accreditation requirements there is no specified percentage of the minimum 225 Complementary Studies AUs that must be specifically allocated to engineering ethics [2]. This is where uncertainty as to the degree of exposure to formal EEE students experience as part of their undergraduate training arises from. Engineering programs may allot drastically different amounts of time to formal EEE, while still satisfying the program accreditation criteria.

\subsection{EEE Exposure in Undergrad Programs}

Formal EEE is delivered to undergraduate students within their program using a variety of strategies, the most common of which are summarized in Table 2 [12].

Table 2: Common EEE delivery strategies in engineering undergraduate programs [12].

\begin{tabular}{|l|l|}
\hline Delivery Type & Characteristics \\
\hline $\begin{array}{l}\text { Embedded } \\
\text { Approach }\end{array}$ & $\begin{array}{l}\text { Engineering faculty members } \\
\text { introduce ethics at their discretion in } \\
\text { technical courses across the } \\
\text { curriculum. }\end{array}$ \\
\hline $\begin{array}{l}\text { Joint Venture } \\
\text { Model }\end{array}$ & $\begin{array}{l}\text { One course is taught by a team of } \\
\text { professors from multiple disciplines. }\end{array}$ \\
\hline $\begin{array}{l}\text { Standalone } \\
\text { Course } \\
\text { (Mandatory) }\end{array}$ & $\begin{array}{l}\text { One independent course is taught on } \\
\text { the topic and is mandatory for all } \\
\text { students in the program. }\end{array}$ \\
\hline $\begin{array}{l}\text { Standalone } \\
\text { Course } \\
\text { (Elective) }\end{array}$ & $\begin{array}{l}\text { One independent course is taught on } \\
\text { the topic and is optional for students to } \\
\text { take. }\end{array}$ \\
\hline
\end{tabular}

Students may be exposed to informal EEE via extracurricular or optional stream activities such as by participating in design teams and clubs, engineering student government, or by directing or attending engineering conferences and workshops. Additionally, a percentage of students partake in internship or co-op programs throughout their degrees which may either require further ethics training or provide experience that may impact their ethical development as engineers [2].

Many universities will use a combination of these delivery methods throughout their engineering programs [12]. The scope of this study will not address the effectiveness of different delivery strategies, but rather the amount of EEE exposure individual students experience as a result of diverse program plans.

\subsection{Canadian EEE Curriculum and Objectives}

Currently, aside from the general objective decreed by $\mathrm{CEAB}$ Graduate Attribute 10, there is no standardized engineering ethics curriculum in Canada $[2,21]$. This is due to various factors, the foremost being that there is not universally agreed upon interpretation of the objectives of EEE [12, 15, 20]. The consensus between the vast majority of viewpoints on EEE curriculum is that at a minimum, professional ethics should be taught to students $[12,15,20,21]$. To summarize, this breaks down to:

1. Awareness of ethical responsibility as an engineer.

2. Knowledge about professional engineering codes and regulations.

3. Ability to apply knowledge of codes and regulations for ethical decision making within an engineering context.

Although the above content may be a solid foundation for engineering ethics curriculum, many scholars believe that this content does not cover the breadth of the complex nature of engineering ethics within a societal context $[2,4,11,15]$. Harris et al. proposed a list of more in depth potential objectives for EEE [6]:

1. Stimulate the ethical imagination of students

2. Help students recognize ethical issues

3. Help students analyze key ethical concepts and principles

4. Help students deal with ethical disagreement, ambiguity and vagueness

5. Encourage students to take ethical responsibility seriously

6. Increase student sensitivity to ethical issues

7. Increase student knowledge of relevant standards

8. Improve ethical judgement

9. Increase ethical will-power

Both Haws and Lynch discussed key elements of EEE content that may extend beyond those that fall solely under professional ethics $[10,14]$ :

1. Professional engineering ethical codes

2. Theoretical reasoning and moral theories

3. Humanist readings

4. Case studies

5. Ethical heuristics

6. Service learning 
Another way to think about engineering ethics is to break professional ethics down philosophically into micro-ethics and macro-ethics. As summarized by $\mathrm{Li}$ and $\mathrm{Fu}$, "micro-ethics considers individuals and internal relations of the engineering profession" whereas, "Macro-ethics concerns the collective social responsibility of the profession to make societal decisions about technology or the social context in which engineers are practicing" $[11,12]$. In the past, micro-ethics have been the primary focus of EEE curriculum, but many engineers see micro-ethics as an oversimplification of engineering ethics and believe that curriculum should shift to incorporate a macro-ethics focused approach $[4,11,15]$.

To summarize, although there is common ground between perspectives, there is clearly varied interpretation of what the curriculum and objectives of EEE should consist of. It is important to understand the array of present interpretations of EEE within Canada to help to develop clear purpose behind Canadian EEE.

\section{PROPOSED RESEARCH DIRECTION}

\subsection{Proposed Research Questions}

This study aims to primarily answer the following questions:

1. How much exposure do engineering students have to EEE throughout their undergraduate careers?

1.1 How much formal exposure do they have to EEE?

1.2 How much informal exposure do they have to EEE?

2. What ethics content do students perceive they are being exposed to throughout EEE?

3. Is there a relationship between the amount of EEE that engineering students experience and their ethical behaviour within an engineering context?

4. Do engineering students perceive EEE to have impacted their ethical beliefs?

\subsection{Proposed Site of Research Study}

This proposed site for this study is across Canadian universities with accredited undergraduate engineering programs. Performing this study at a national scale would be beneficial as it would identify variance in how EEE is being implemented and interpreted throughout Canada.

It is noteworthy that many schools have multiple engineering disciplines with various sub-streams. Each discipline and sub-stream may have different program structures, and so it is possible that within individual schools there will be variation in the amount and type of exposure students have had to EEE. It will be important to investigate trends based upon program path within schools, as well as between schools within Canada as a whole.

\subsection{Proposed Participants of Research Study}

The participants of this study will include engineering students that are studying at Canadian universities at various points in their undergraduate degrees. These groups have been divided into three primary categories:

- $\quad$ Group A - $1^{\text {st }}$ Year Engineering Students (pre-class) - At the start of their degree these students will generally have had no formal engineering ethics education.

- $\quad$ Group $B-2^{\text {nd }}-3^{\text {rd }}$ Year Engineering Students These students will be in the midst of their undergraduate engineering degrees and have experienced various amounts of EEE based upon their school, discipline, sub-stream, and extracurricular or optional stream activities.

- Group C - Graduating Engineering Students (end of term) - These students will have experienced at least the minimum amount of EEE to graduate from an accredited engineering program.

The intention behind using these students as participants is to target students at key points within their engineering undergraduate career in order to investigate the level of exposure they have had to EEE and observe any trends that may appear as a result of this.

\subsection{Proposed Methods of Research Study}

The proposed study is mixed-methods using primarily a survey to collect both quantitative and qualitative data. Secondary methods that may be used include focus groups or interviews.

The first section of the survey will be used to gather demographic information about the participant. This will include identifying variables such as age, gender, year of program, discipline, sub-stream, etc. More research will be done to determine the demographic information that will be necessary to analyze data trends, but the primary reason for collecting demographic data will be to determine what group a participant falls into, as described in section 3.3.

The second section of the survey will determine the amount of EEE exposure the participant has had. Students will be asked to estimate the number of hours they spend on engineering ethics in lecture/lab/tutorial over their degree to date. By identifying the amount of exposure students have to formal EEE at various 
universities, it will be possible to approximate a range for how many AUs of the potential 225 are currently being allotted to engineering ethics by numerous programs. This will help to determine the degree of variance between programs, and also may be beneficial to help further inform program accreditation requirements. If there are trends that show significant differences between programs, this may be a basis for further accreditation requirements to be defined. Furthermore, students will be asked to discuss any informal EEE experiences they have been exposed to that they perceive to have impacted their ethical development as engineers.

Additionally, this part of the survey will identify what type of ethics content engineering students perceive they have been exposed to, as discussed in Section 2.4 of this paper. Examples of the type of content that will be asked about include ethical codes and regulations, ethical reasoning, case studies, etc. Identifying what curriculum elements of EEE students perceive they have been exposed to, will develop a clearer understanding of how the objectives of engineering ethics are currently being interpreted by universities across Canada. This aspect of the study may also be useful to identify if there is a discrepancy between student and faculty perceptions of the EEE curriculum, as well as help inform further definition of EEE curriculum and objectives.

The third component of the survey will strive to investigate students' ethical behaviour in an engineering context. This section will mainly consist of application of the content generally taught in EEE by Canadian universities. Students will be given various case studies where they have to decide how they would act as an engineer. These cases will resemble common ethical dilemmas, situated in an engineering context. An example would be the classic Trolley Problem, in the engineering context of self-driving cars [22]. These questions will likely be delivered using multiple choice questions primarily with an 'Other' option where they may provide alternative answers. Responses will be analysed to see if there is a relationship between an individual's professional ethical decision making, their amount of exposure to EEE, and the type of EEE content they perceived being exposed to. This will provide insight into the impact EEE is having upon engineering students' ethical development. It is important to observe these trends on a national scale to determine if current EEE practices are producing graduating engineering students that satisfy CEAB Graduate Attribute 10.

The final part of the survey will be a qualitative component that will investigate whether engineering students feel that their EEE has impacted their ethical beliefs. This element of the survey shall be more exploratory and open-ended with the objective being to identify how students perceive EEE to have impacted their beliefs.

\section{CONCLUSIONS}

There is a clear need for more research to be done within the field of engineering ethics education to help better understand the ethical development of engineers. This paper has summarized some of the research relevant to informing a study to investigate the present state of EEE in Canada and the impact that current EEE practices are having on engineering students.

By gaining a better understanding of how EEE exposure impacts individuals, it is possible to better understand the influence of current EEE practices, and to continue to develop a basis for impactful engineering ethics education. This research is vital as society ultimately benefits from engineers with a strong ethical foundation.

\section{REFERENCES}

[1] Professional Engineers Act, Ontario R.R.O. 1990, REGULATION 941, 2018.

[2] C. E. A. Board, "2018 Accreditation Criteria and Procedures," Engineers Canada, 2018. [Online]. Available:

https://engineerscanada.ca/sites/default/files/accredita tion/Accreditation-criteria-procedures-2018.pdf

[3] C. E. Q. Board, "Public Guideling on the code of ethics," March 2016. [Online]. Available: https://engineerscanada.ca/publications/publicguideline-on-the-code-of-ethics\#-fundamentalprinciples

[4] L. L. Bucciarelli, "Ethics and Engineering Education," Science and Engineering Ethics, vol. 18, no. 2, pp. 141-149, 2008.

[5] E. Canada, "About Accreditation," Engineers Canada, November 2018 vol.

https://engineerscanada.ca/accreditation/aboutaccreditation. [Online]. Available: https://engineerscanada.ca/sites/default/files/accredita tion/Accreditation-criteria-procedures-2018.pdf

[6] J. Charles Edwin Harris, Michael Davis, Michael S. Pritchard, Michael J. Rabins, "Engineering Ethics: What? Why? How? And When?," Journal of

Engineering Education, vol. 85, no. 2, pp. 93-96, 1996. [Online]. Available:

https://onlinelibrary.wiley.com/doi/abs/10.1002/j.216 $\underline{8-}$

9830.1996.tb00216.x? casa token $=4$ TBmNZy17UIA AAAA:m8JksEN1c82P6qTV20fN1YoLceL9kd697A S-

zxay8LWnoBCKyMwajj9wUKta4Ty3d3JM7oyaqL HXI.

[7] D. R. Cindy Rottmann, Robin Sacks, Mike Klassen, "Engineering Ethics Education: More than a CEAB

Requirement," presented at the Canadian Engineering Education Association, Hamilton, 2015. 
[8] E. A. Commission, "Criteria for Accrediting Engineering Programs," ABET, Baltimore, MD, 2015. [Online]. Available:

https://www.abet.org/accreditation/accreditationcriteria/criteria-for-accrediting-engineeringprograms-2016-2017/

[9] E. A. Commission. "Criteria for Accrediting Engineering Programs, 2016 - 2017." Engineering Accreditation Commission.

https://www.abet.org/accreditation/accreditationcriteria/criteria-for-accrediting-engineeringprograms-2016-2017/\#definitions (accessed.

[10] D. R. Haws, "Ethics Instruction in Engineering Education: A (Mini) Meta-Analysis," Journal of Engineering Education, vol. 90, no. 2, pp. 223-229, 2001.

[11] J. R. Herkert, "Ways of Thinking about and Teaching Ethical Problem Solving: Microethics and Macroethics in Engineering," Science and Engineering Ethics, vol. 11, no. 3, pp. 373-385, 2005. [Online]. Available: https://link.springer.com/content/pdf/10.1007/s11948 -005-0006-3.pdf.

[12] S. F. J. Li, "A Systematic Approach to Engineering Ethics Education," Science and Engineering Ethics, vol. 18, no. 2, pp. 339-349, 2012. [Online].

Available:

https://link.springer.com/article/10.1007/s11948-0109249-8.

[13] P. L. J. S. Cicek, S. Ingram, "Examining Fourth Year Engineering Student Perceptions of Graduate Attribute Competencies: Year Two," presented at the Canadian Engineering Education Association, Canmore, 2014.

[14] W. T. Lynch, "Teaching Engineering Ethics in the United States," IEEE Technology and Society Magazine, vol. 16, no. 4, pp. 27-36, 1998.

[15] B. Newberry, "The Dilemma of Ethics in Engineering Education," Science and Engineering Ethics, vol. 10, no. 2, pp. 343-351, 2004. [Online]. Available: https://link-springercom.proxy.queensu.ca/content/pdf/10.1007/s11948004-0030-8.pdf.

[16] C. P. A. o. Ontario, "A Simple Guide to CPD Requriements," 2019. [Online]. Available: https://media.cpaontario.ca/cpa-members/pdfs/CPDRequirements-Guide.pdf

[17] L. S. o. Ontario. "Continuing Professional Development Requirement." https://lso.ca/lawyers/enhancingcompetence/continuing-professional-developmentrequirement (accessed.

[18] (2019). Acts, Regulations and By-laws. [Online] Available: https://www.peo.on.ca/about-peo/what-ispeo/acts-regulations-and-laws

[19] (2020). Practice Evaluation and Knowledge Program $F A Q$. [Online] Available: https://www.peo.on.ca/knowledge-centre/frequentlyasked-questions/licence-holders-faq/practiceevaluation-and-knowledge\#collapse 11

[20] S. K. A. Pfatteicher, "Teaching vs. Preaching: EC2000 and the Engineering Education Dilemma,"
Journal of Engineering Education, vol. 90, no. 2, pp. 137-142, 2001.

[21] A. Roncin, "Thoughts on Engineering Ethics Education in Canada," presented at the Canadian Engineering Education Association, Montreal, 2013.

[22] J. S. Sven Nyhom, "The Ethics of AccidentAlgorithms for Self-Driving Cars: an Applied Trolley Problem?," Ethical Theory and Moral Practice, vol. 19, pp. 1275 - 1289, 2016. [Online]. Available: https://link.springer.com/article/10.1007/s 10677-0169745-2\#citeas. 